\title{
Radiographic evaluation of the dental condition of elderly people treated at a Brazilian public university
}

\section{Francisco Ivison Rodrigues Limeira', Daniela Pita de Melo', Daliana Queiroga de Castro Gomes², Sérgio d'Ávila Lins Bezerra Cavalcantiti ${ }^{3}$ Patrícia Meira Bento ${ }^{4}$}

\author{
${ }^{1}$ Area of Dental Radiology, Department of Dentistry, State University of Paraiba, Campina Grande, PB, Brazil \\ ${ }^{2}$ Area of Oral Diagnosis, Department of Dentistry, State University of Paraiba, Campina Grande, PB, Brazil \\ ${ }^{3}$ Area of Public Health, Department of Dentistry, State University of Paraiba, Campina Grande, PB, Brazil \\ ${ }^{4}$ Area of Oral Pathology, Department of Dentistry, State University of Paraiba, Campina Grande, PB, Brazil
}

Received for publication: September 29, 2013 Accepted: December 17, 2013

Correspondence to: Francisco Ivison Rodrigues Limeira Avenida Baraunas, 351, CEP: 58109-753 Universidade Estadual da Paraíba Campus Universitário Bodocongó, Campina Grande, Paraíba, Brasil Phone: +558388579262 / +558396113409

E-mail: ivisonodontoce@hotmail.com

\begin{abstract}
Aim: To assess the dental status of elderly patients examined in the clinical dentistry course of a Brazilian public university. Methods: An observational and descriptive study based on the analysis of panoramic radiographs. The sample consisted of 60 elderly patients who met the inclusion criteria. Two observers who had been trained in appropriate conditions performed the radiographic analysis. Data were stored in a specific form, recorded in a database and analyzed using descriptive statistics (measures of central tendency and variability) and inferential statistics (Mann-Whitney U test, Kruskal-Wallis test, Chi-square analysis and calculation of the Cramer's $\checkmark$ coefficient). Results: Most patients had at least one tooth in the oral cavity $(71.7 \%)$, while $28.3 \%$ were totally edentulous, an average of 10.5 teeth per individual. The average number of teeth was 11.36 in males and 9.89 in females. The number of healthy teeth was 328 (5.47 per patient). In this study, $88.3 \%$ of the subjects had periodontal bone loss, with prevalence of moderate $(35.0 \%)$ and severe $(28.3 \%)$ bone loss. Conclusions: Given the high incidence of edentulous individuals, the high number of restored teeth and poor periodontal conditions, it is concluded that the overall oral health status of the evaluated elderly subjects is poor.
\end{abstract}

Keywords: oral health, panoramic radiography, epidemiology.

\section{Introduction}

According to the World Health Organization (WHO), the chronological level of 60 years of age and over is used to define the elderly population in developing countries ${ }^{1}$.

It is estimated that there are approximately 17.6 million elderly Brazilians and that by the year 2025, the country will have the sixth largest elderly population in the world, over 30 million people ${ }^{2,3}$. Among the main challenges faced by the healthcare system is the generation of new demands ${ }^{4}$. Regarding oral health, such changes have predictable consequences and should be instrumental in defining effective measures to prevent disease and loss of teeth along an individual's lifetime 5 . Preliminary results of the most recently released survey showed that more than 3 million seniors need complete dentures and other 4 million need partial dentures ${ }^{6}$. 
Aging is an ongoing and complex process that occurs in all types of body cells, although it presents special features in certain organs and systems ${ }^{7}$. According to Matos et al. ${ }^{8}$ and Meloto et al. ${ }^{9}$, the aging process is associated with many changes in the mouth, some of them related to systemic problems (cardiovascular and cerebrovascular diseases, diabetes mellitus, oral cancer, osteoporosis, Alzheimer's and Parkinson's diseases) and their treatments, where the loss of teeth is not a consequence of aging but rather the result of complex interaction between dental diseases and the lack of preventive measures implemented either by the dentist or the individual. Thus, dental professionals must understand the complexities inherent to older people, their special needs and their ability to undergo and respond to care.

Many of these senior citizens still have their natural teeth, requiring significant levels of maintenance, which is beneficial to their overall health, considering the advantages of better nutrition and life quality ${ }^{10}$. However, these benefits can only be maintained if the individual's dental health is preserved, increasing the emphasis on preventive care ${ }^{11}$.

Given the importance of understanding the oral health status of this population, the aim of this study was to survey the dental status of elderly patients examined in the clinical dentistry course of a Brazilian public university.

\section{Material and methods}

This is an observational and descriptive study based on the analysis of panoramic radiographs of elderly patients (people with 60 years or more) examined in the clinical dentistry course of a public university in Brazil from August 2009 to June 2010. During this period, 78 senior citizens were examined, but some panoramic radiographs without conditions for a good interpretation were excluded.

The sample consisted of 60 senior citizens of both genders, enrolled by a non-probabilistic sampling, who had panoramic radiography as prerequisite for a treatment plan.

The research project was approved by UEPB Ethics Committee with CAAE (Presentation of Certificate of Appreciation for Ethics) protocol number 0539.0.133.00009, according to Resolution 466/12 of the CNS (National Health Council).

Two double-blinded investigators who had received previous theoretical and practical training to ensure a consistent interpretation of the established criteria performed the radiographic evaluation. A pilot study was conducted with 20 elders to test the methodology and instruments to be used. Three weeks later this group was re-evaluated. The calibration for the radiographic analysis was carried out according to the recommendations of a dental radiologist, and the Kappa agreement index was 0.91.

The radiographic interpretation was performed in the same light box, with appropriate light intensity, using a $4 \mathrm{x}$ magnifying lens and a sequence by quadrants. All information obtained in the radiographic examinations was recorded on a structured form containing each individual's socioeconomic information, including age, gender, and ethnicity, as well as the radiographic findings, describing the condition of the patient's teeth and oral bone structures.

In the radiographic analysis were considered as healthy teeth without evidence of caries (radiolucent image) or radiopaque restoration. The teeth restored with amalgam, metal crowns, ceramic metals, or other radiopaque materials were considered as radiopaque restoration. Teeth with healthy roots were included in this study, and residual roots were not included in the number of present teeth. The following scores were adopted for the classification of periodontal bone loss in the periodontal assessment: 0 no bone loss; 1 cervical bone loss; 2 bone loss in the middle third; 3 bone loss in the apical third.

The data were recorded using the Statistical Package for Social Sciences (SPSS) for Windows ${ }^{\circledR}$, version 15.0, and analyzed using descriptive statistics (measures of central tendency and variability) and inferential statistics (MannWhitney U test, Kruskal-Wallis test, Chi-square analysis and calculation of the Cramer's V coefficient). Finally, a 95\% confidence interval at a 5\% significance level $(\mathrm{p}<0.05)$ was set for data analysis.

\section{Results}

In the examined sample, most individuals $(58.3 \%)$ were female and aged 60"64 years $(43.3 \%)$. The percentages corresponding to the other age groups were: $65 " 69$ years, $30.0 \%$; 70 "74 years, $13.3 \%$; and 75 or older, $13.3 \%$. Among the participants, $56.7 \%$ had at least one tooth in both arches, $28.3 \%$ were totally edentulous, $13.3 \%$ were edentulous in the maxillary arch, and $1.7 \%$ in the mandibular arch.

Regarding the teeth present, it was verified that out of a total of 630, there were 293 teeth in the maxillary arch and 337 teeth in the mandibular arch, resulting in a mean of $10.5(\mathrm{SD}=8.74)$ teeth per individual. Among the participants, $20 \%$ had 1"10 teeth, $46.7 \%$ had $11 " 20$ teeth, and $5.0 \%$ had over 20 teeth. The mean number of teeth in males was 11.36 and 9.89 in females. Despite this variation, there were no statistically significant differences by gender $(\mathrm{U}=393.5, \mathrm{p}=0504)($ Table 1$)$

Regarding dental characteristics, the total sum of healthy teeth was 328 (5.47 per patient). Residual root tissue was present in $26.7 \%$ of participants ( 0.33 per patient), and radiopaque fillings were present in $70.0 \%$ of patients $(2.87$ per patient) (Table 2).

There was a progressive decrease in the number of teeth corresponding to higher age. The average number of teeth present in those aged 60"64 years was 15.23 teeth, while the average decreased to 11.50 in those aged 65"69 years, and, more drastically, to 1.75 or 1.63 in the group aged 70 and above (Table 2). This difference was statistically significant $(\mathrm{KW}=24.09, \mathrm{p}<0.001)$ (Table 3).

Bone loss occurred in $88.3 \%$ of the participant individuals at the following levels: cervical/mild, $25.0 \%$; medium/ moderate, 35.0\%; and apical/severe, 28.3\% (Table 4).

Tooth loss was statistically correlated with the age of participants $\left(\div^{2}=10.363, \mathrm{p}=0.016\right)$. The results suggested 
Table 1: Distribution of the total number of teeth depending on age and gender. Campina Grande, PB, Brazil. 2013

\begin{tabular}{c|ccccccc}
\hline \multirow{2}{*}{$\begin{array}{c}\text { Age } \\
\text { group }\end{array}$} & \multicolumn{4}{|c}{ Male } & \multicolumn{5}{c}{ Female } & Inferential values \\
\cline { 2 - 7 } & $\mathrm{f}$ & $\%$ & $\mathrm{M} \pm \mathrm{SD}$ & $\mathrm{f}$ & $\%$ & $\mathrm{M} \pm \mathrm{SD}$ & \\
\hline $\mathbf{6 0 - 6 4}$ & 12 & 20.0 & $15.58 \pm 6.47$ & 14 & 23.3 & $14.93 \pm 9.08$ & $\mathrm{U}=76.00 ; \mathrm{p}=0.678$ \\
& & & & & & & \\
$\mathbf{6 5 - 6 9}$ & 6 & 10.0 & $13.67 \pm 5.78$ & 12 & 20.0 & $10.42 \pm 6.55$ & $\mathrm{U}=22.50 ; \mathrm{p}=0.202$ \\
$\mathbf{7 0 - 7 4}$ & 3 & 5.0 & $3.33 \pm 3.05$ & 5 & 8.3 & $0.80 \pm 1.09$ & $\mathrm{U}=3.50 ; \mathrm{p}=0.201$ \\
$\mathbf{7 5 - +}$ & 4 & 6.7 & $1.25 \pm 2.50$ & 4 & 6.7 & $2.00 \pm 4.00$ & $\mathrm{U}=7.50 ; \mathrm{p}=0.850$ \\
\hline Total & 25 & 41.7 & $11.36 \pm 7.94$ & 35 & 58.3 & $9.89 \pm 8.77$ & $\mathrm{U}=393.50 ;=0.504$ \\
\hline
\end{tabular}

Source: Clinical Dentistry of the State University of Paraiba.

Table 2: Evaluation of teeth for health, presence of radiopaque restorations and residual roots. Campina Grande, PB, Brazil. 2013

\begin{tabular}{lccc}
\hline Characteristics & f (total) & \% (total) & Mean/patient \\
Healthy & 328 & 63.08 & 5.47 \\
\hline $\begin{array}{l}\text { Radiopaque } \\
\text { restorations }\end{array}$ & 172 & 33.07 & 2.87 \\
\hline Residual root & 20 & & \\
\hline Total & 520 & 3.85 & 0.33 \\
\hline
\end{tabular}

Source: Clinical Dentistry of the State University of Paraiba.

Table 3: Distribution of teeth according to age and tooth characteristics. Campina Grande, PB, Brazil. 2013

\begin{tabular}{|c|c|c|c|c|c|}
\hline \multirow{2}{*}{$\begin{array}{l}\text { Age group } \\
\text { Characteristics }\end{array}$} & $60-64$ & $65-69$ & $70-74$ & 75 years - + & \multirow{2}{*}{$\begin{array}{c}\text { Inferencial } \\
\text { Valores }\end{array}$} \\
\hline & $M \pm S D$ & $\mathrm{M} \pm \mathrm{SD}$ & $\mathrm{M} \pm \mathrm{SD}$ & $\mathrm{M} \pm \mathrm{SD}$ & \\
\hline Teeth & $15.23 \pm 7.84$ & $11.50 \pm 6.33$ & $1.75 \pm 2.25$ & $1.63 \pm 3.11$ & $\begin{array}{l}K W=24.09 ; \\
p<0.001^{* *}\end{array}$ \\
\hline Healthy & $8.81 \pm 5.66$ & $5.28 \pm 3.83$ & $0.38 \pm 0.74$ & $0.13 \pm 0.35$ & $\begin{array}{l}K W=25.07 \\
p<0.001^{* *}\end{array}$ \\
\hline Root status & $0.38 \pm 0.75$ & $0.39 \pm 0.50$ & $0.25 \pm 0.46$ & $0.13 \pm 0.35$ & $\begin{array}{c}\mathrm{KW}=1.77 \\
\mathrm{p}=0.621\end{array}$ \\
\hline $\begin{array}{l}\text { Radiopaque } \\
\text { restorations }\end{array}$ & $3.62 \pm 2.26$ & $3.72 \pm 2.21$ & $0.75 \pm 1.03$ & $0.63 \pm 1.18$ & $\begin{array}{l}K W=18.45 \\
p<0.001^{* *}\end{array}$ \\
\hline
\end{tabular}

Source: Clinical Dentistry of the State University of Paraiba.

${ }^{*}$ Statistically significant difference at $1 \%$.

Table 4: Bone loss according to the age. Campina Grande, PB, Brazil. 2013

\begin{tabular}{c|ccccccccccc}
\hline \multirow{2}{*}{ Levels } & \multicolumn{2}{|c}{$\begin{array}{c}60-64 \\
\text { years }\end{array}$} & \multicolumn{2}{c}{$\begin{array}{c}65-69 \\
\text { years }\end{array}$} & \multicolumn{2}{c}{$\begin{array}{c}70-74 \\
\text { years }\end{array}$} & $\mathbf{7 5}$ years - + & \multirow{2}{*}{ Total } \\
\cline { 2 - 12 } & $\mathbf{n}$ & $\%$ & $\mathbf{n}$ & $\%$ & $\mathbf{n}$ & $\%$ & $\mathbf{n}$ & $\%$ & $\mathbf{n}$ & $\%$ \\
\hline No loss & $7^{* *}$ & 11.7 & 0 & 0.0 & 0 & 0.0 & 0 & 0.0 & 7 & 11.7 \\
Cervical third & 8 & 13.3 & 7 & 11.7 & 0 & 0.0 & 0 & 0.0 & 15 & 25.0 \\
Middle third & 9 & 15.0 & 9 & 15.0 & 3 & 5.0 & 0 & 0.0 & 21 & 35.0 \\
Apical third & 2 & 3.3 & 2 & 3.3 & $5^{* *}$ & 8.3 & $8^{* *}$ & 13.3 & 17 & 28.3 \\
\hline Total & 26 & 43.34 & 18 & 30.00 & 8 & 13.33 & 8 & 13.33 & 60 & 100.00 \\
\hline
\end{tabular}

Source: Clinical dentistry of the State University of Paraiba.

${ }^{* *}$ Statistically significant difference at $1 \%$. 
a moderate association $(\mathrm{V}=0.486)$ and statistical significance $\left(\div{ }^{2}=42.453, \mathrm{p}<0.001\right)$, mainly regarding the apical loss in those aged 70 years and older.

\section{Discussion}

In Brazil, there are few studies assessing the current oral health status of the elderly. This may be due to the low demand for dental treatment by the elderly, who consider poor oral health an inevitable consequence of aging. The extant studies show edentulism, coronal and root carious lesions, periodontopathy and soft-tissue lesions to be the most frequent changes in this population ${ }^{12-13}$.

Regarding the gender of the participants, most were female $(58.3 \%)$, corroborating a strong trend in the recent epidemiological studies in elderly populations ${ }^{13-16}$. The greater female presence may be associated with the phenomenon of the "feminization of old age", as women are majority in the world's elderly population, and there is a global difference in life expectancy between the genders. Mastroeni et al. ${ }^{18}$ and Costa et al. ${ }^{19}$, affirm that the current predominance of women over 60 years, in proportions that increase with age, is an important aspect to consider in the planning of local programs to assist senior citizens.

The age group with the largest number of participants was the 60-64year-old age group, which represented $43.3 \%$ of the total. The behavior was similar in both genders. However, the subgroup that grew most rapidly in the last 10 years is the group aged 75 years or more, according to data from the American Geriatrics Society ${ }^{20}$.

In the analysis of oral conditions, it was observed that $28.3 \%$ showed total edentulism, similar to the findings of Talwar, Malik and Sharma ${ }^{21}$. Other studies show an even worse situation, such as the one reported by Costa et al. ${ }^{19}$ (31,1\%), Simunkovic et al. $^{22}(45,3 \%)$ and Mack et al. ${ }^{23}$ : $16 \%$ in the age group from $60-65$ years and $30 \%$ in the age range from 75 to 79 years.

Other studies that evaluated the oral health status of the elderly population by radiographs also found a high incidence of total edentulism, such as the study conducted by Soikkonen et al. ${ }^{24}$, who evaluated the oral radiographs of 293 senior citizens between 76 and 86 years old and found, that 124 were completely edentulous. Additionally, the study conducted by Karhunen et al. ${ }^{25}$ with radiographic evaluation of the dental health of men aged 33"69 years by panoramic radiographs taken in autopsies, found that $17.4 \%$ of men were completely edentulous.

According to Alcantara et al. ${ }^{17}$, the suboptimal status of the elderly Brazilian population's oral health is due to the lack of preventive attitudes by the dentists, who, for some years performed unnecessary extractions that were possibly iatrogenic, and this increased the rate of edentulism in the country. The partial or total loss of teeth is a large part of an irreversible and cumulative process. According to Rihs et al. ${ }^{26}$ this scenario may reflect the difficulty of access to dental services for a large portion of the Brazilian population or even the lack of importance assigned by these individuals to oral health along their lives.
Based on the situations observed in the current study, it is believed that the poor oral health conditions arise from the fact that there has been no policy for oral health education for this population in their lives. This implies that this population does not actively seek dental care because they are not aware that poor dental health is not a necessary part of aging.

Regarding the teeth found present in the study, there was a total of 630 teeth, with an average of 10.5 teeth per individual. The average number of teeth in males was 11.36 and 9.89 in females. The healthy teeth amounted to a total of 328 , an average of 5.47 per patient, and 172 , or an average of 2.87 per participant showing radiopaque restoration. These results are similar to those found in other studies that show poor oral conditions, such as Mack et al. ${ }^{23}$. In their study, 26\% of the participants aged 60"69 years and $17 \%$ of those in the aged $70-79$ years had the examined teeth restored, and dental caries were found in $2 \%$ of the teeth in both age groups. Simunkovic et al. ${ }^{22}$ reported that the average number of decayed teeth was 1.03 per participant and 0.74 restored teeth per participant, and approximately 9 teeth per person needed treatment.

Periodontal disease, expressed as gingival inflammation and retraction, tooth root exposure, and loss of alveolar bone structure supporting the teeth, was found as a major cause of tooth loss in adults ${ }^{5}$. In their study, Carneiro et al. ${ }^{12}$ selected 293 subjects, stratified according to age and gender. More than $94 \%$ of the subjects showed calculus as the ultimate sign of periodontal neglect; only $1.8 \%$ had healthy periodontal conditions, and $33.3 \%$ had insertion losses of 6"8 mm. In this study, $88.3 \%$ of the elders had periodontal bone loss, which varied from moderate $(35.0 \%)$ to severe $(28.3 \%)$, similar to the study of Mack et al. ${ }^{23}$ where the prevalence of periodontal disease was higher in men and among the younger subjects (men aged 60-69 years: $85 \%$ vs. $71 \%$ in 70-79-year-old men; women aged 60-69 years: $71 \%$ vs. $62 \%$ in 70-79-years), which is possibly associated with oral hygiene, according to Viana et al. ${ }^{16}$.

Aging with dignity is a desire in every society, but this will only be achieved when it is translated into a better quality of life. The National Oral Health Policy of the Ministry of Health emphasizes its goal to increase the number of Brazilian adults and senior citizens who possess a satisfactory quality of life level relative to their oral health. However, according to Saintrain et al. ${ }^{27}$ and Matheus et al. ${ }^{28}$, the dentistry area as a whole should incorporate a new mind frame in training professionals, based on interdisciplinary and comprehensive health care for the elderly individuals, to meet the demands of patients in this age group. This would require training professionals to specialize in geriatric dentistry, specific to all levels of senior citizens' care, involving not only the professional team, but also the senior citizens and their families, the authorities and the community through more objective and effective integrated actions.

Given the high incidence of edentulism, the large number of restored teeth and poor periodontal conditions found in elderly test subjects, it is clear that there is a need to take steps in the community towards providing full and comprehensive oral health care to senior citizens. 


\section{Acknowledgements}

The authors are grateful to the National Council for Scientific and Technological Development (CNPq) for financial support.

\section{References}

1. WHO Library Cataloguing in Publication Data. Integrating poverty and gender into health programmes: a sourcebook for health professionals: module on ageing. Geneva: WHO; 2006.

2. Carvalho JAM, Garcia RA. The aging process in the Brazilian population: a demographic approach. Reports in Public Health. 2003; 19: 725-33.

3. Lima-Costa MF, Veras R. Aging and public health. Reports in Public Health. 2003; 19: 700-1.

4. Pan American Health Organization. Managerial network of informations for health. Report of situations and trends: demographic and health. Brasilia: 2009.

5. Cardoso EM, Parente RCP, Vettore MV, Rebelo MAB. Oral health conditions of elderly residents in the city of Manaus, Amazonas: estimates by sex. Brazilian Journal of Epidemiology. 2011; 14: 131-40.

6. Brazil. Health of Ministry. Department of health care. Department of primary care. SB Brasil 2010. National Survey of Oral Health: preliminary results. Brasilia: Health of Ministry; 2011.

7. Oliveira MC, Schoffen JPF. Oxidative Stress Action in Cellular Aging. Braz Arch Biol Technol. 2010; 53: 1333-42.

8. Matos FD, Freitas EV, Py L et al. Diseases of high digestive tract. In: Freitas EV, Py L, Cancado FAX et al. Treaty of Geriatrics and Gerontology. Brasil: Guanabara Koogan, 2006: 641-642.

9. Meloto CB, Rizzatti-Barbosa CM, Gomes SGF, Custodio W. Dental practice implications of systemic diseases affecting the elderly: a literature review. Braz J Oral Sci. 2012; 27: 1691-1699.

10. Haikal DS, Paula AMB, Martins AMEBL, Moreira AN, Ferreira EF. Selfperception of oral health and impact on quality of life among the elderly: a quantitative-qualitative approach. Ciência \& Saúde Coletiva. 2011; 16 : 3317-3329.

11. Newton JP. Oral health for older people. Gerodontology. 2006; 23: 1-2.

12. Carneiro RMV, Silva DD, Sousa MLS, Wada RS. Oral health of institutionalized elderly in the eastern zone of São Paulo, Brazil, 1999. Reports in Public Health. 2005; 21: 1709-1716.

13. Andrade FB, Lebrão ML, Santos JLF, Duarte YAO. Relationship between oral health and frailty in community-dwelling elderly individuals in Brazil. J Am Geriatr Soc. 2013; 61: 809-814.

14. Rodrigues SM, Oliveira AC, Vargas AMD, Moreira AN, Ferreira EF. Implications of edentulism on quality of life among elderly. Int J Environ Res Public Health. 2012; 9: 100-109.

15. Lemos MMC, Zanin L, Jorge MLR, Flório FM. Oral health conditions and self-perception among edentulous individuals with different prosthetic status. Braz J Oral Sci. 2013; 12: 5-10.

16. Viana LRF, Castro CP, Pereira HBW, Pereira, AFV, Lopes FF. Is depression associated with periodontal status in elderly? Braz J Oral Sci. 2013; $12: 20-22$.

17. Alcântara CM, Dias CA, Rodrigues SM, Reis FA. Comparative study of the oral health status of non-institutionalized elderly from Governador Valadares-MG, with the goal proposed by the World Health Organization, 2010. Physis. 2011; 21: 1023-1044.

18. Mastroeni MF, Erzinger GS, Mastroeni SSBS, Silva NN, Marucci MFN. Demographic profile of the elderly in the city of Joinville, Santa Catarina: a household survey. Brazilian Journal of Epidemiology. 2007; 10:190-201.

19. Costa AM, Guimarães MCM, Pedrosa SP, Nóbrega OT, Bezerra ACB. Oral health status of elderly women from the Brazilian Federal District. Ciência \& Saúde Coletiva. 2010; 15: 2207-2213.
20. American Geriatrics Society. Geriatrics in Brazil: A Big Country with Big Opportunities. J Am Geriatr Soc. 2005; 53: 2018-2022.

21. Talwar M, Malik G, Sharma S. Prevalence of dental caries and periodontal disease in the elderly of chandigarh -A hospital based study. J Indian Dent Assoc. 2012; 6: 78-82

22. Simunkoviæ SK, Boras VV, Panduriæ J, Ziliæ IA. Oral health among institutionalized elderly in Zagreb, Croatia. Gerodontology. 2005; 22: 238-241.

23. Mack F, Mojon P, Budtz-Jorgensen E, Kocher T, Splieth C, Schwahn C, et al. Caries and periodontal disease of the elderly in Pomerania, Germany: results of the Study of Health in Pomerania. Gerodontology. 2004; 21: 27-36.

24. Soikkonen K, Wolf J, Salo T, Tilvis R. Radiographic periodontal attachment loss as an indicator of death risk in the elderly. J Clin Periodontol. 2000; 27: 87-92.

25. Karhunen V, Forss H, Goebeler S, Huhtala H, Ilveskoski E, Kajander O, etal. Radiographic assessment of dental health in middle-aged men following sudden cardiac death. J Dent Res. 2006; 1: 89-93.

26. Rihs LB, Silva DD, Sousa MLR. Dental caries in an elderly population in Brasil. J Appl Oral Sci. 2009; 17: 8-12.

27. Saintrain MVL, Souza EHA, Caldas Júnior AF. Geriatric dentistry in Brazilian universities. Gerodontology. 2006; 23: 231-236.

28. Matthews DC, Clovis JB, Brillant MGS, Filiaggi MJ, McNally ME, Kotzer RD et al. Oral health status of long-term care residents - A vulnerable population. J Can Dent Assoc. 2012; 78: 1-10. 